\title{
Inappropriate Confidence and Retirement Planning: Four Studies with a National Sample
}

\author{
ANDREW M. PARKER ${ }^{1 *}$, WÄNDI BRUINE DE BRUIN ${ }^{2,3}$, JOANNE YOONG $^{4}$ and ROBERT WILLIS ${ }^{5}$ \\ ${ }^{1}$ RAND Corporation, Pittsburgh, PA, USA \\ ${ }^{2}$ Department of Social and Decision Sciences, Carnegie Mellon University, Pittsburgh, PA, USA \\ ${ }^{3}$ Department of Engineering and Public Policy, Carnegie Mellon University, Pittsburgh, PA, USA \\ ${ }^{4}$ RAND Corporation, Arlington, VA, USA \\ ${ }^{5}$ Department of Economics, University of Michigan, Ann Arbor, MI, USA
}

\begin{abstract}
Financial decisions about investing and saving for retirement are increasingly complex, requiring financial knowledge and confidence in that knowledge. Few studies have examined whether direct assessments of individuals' confidence are related to the outcomes of their financial decisions. Here, we analyzed data from a national sample recruited through RAND's American Life Panel, an Internet panel study of US adults aged 18-88 years. We examined the relationship of confidence with self-reported and actual financial decisions, using four different tasks, each performed by overlapping samples of American Life Panel participants. The four tasks were designed by different researchers for different purposes, using different methods to assess confidence. Yet, measures of confidence were correlated across tasks, and results were consistent across methodologies. Confidence and knowledge showed only modest positive correlations. However, even after controlling for actual knowledge, individuals with greater confidence were more likely to report financial planning for retirement and to successfully minimize fees on a hypothetical investment task. Implications for the role of confidence in investment behavior (even if it is unjustified) is discussed. Copyright (C) 2011 John Wiley \& Sons, Ltd.
\end{abstract}

KEY WORDS confidence; knowledge; metacognition; competence; retirement

Financial decisions about investing and saving for retirement are increasingly complex, requiring financial knowledge and confidence in that knowledge. However, few studies have examined whether direct assessments of individuals' confidence, and its correspondence to actual knowledge, are related to the outcomes they experience in life. Among those that have been conducted, some suggest that a lack of correspondence between confidence and knowledge is associated with taking unwise risks, for example among adolescents (Jaccard, Dodge, \& Guilamo-Ramos, 2005; Parker \& Fischhoff, 2005) and among adults playing blackjack (Stone, Rittmayer, \& Parker, 2004). Perhaps as a result of such risk taking, those displaying worse correspondence between confidence and knowledge tend to experience worse real-world decision outcomes (Bruine de Bruin, Parker, \& Fischhoff, 2007). Furthermore, in specific samples of adults, overconfidence has been associated with worse real-world economic performance, with overconfident investors tending to trade more excessively and show worse trading performance (Statman, Thorley, \& Vorkink, 2006), and overconfident chief financial officers tending to make more risky investments, have more long-term debt, and make other seemingly inappropriate business decisions (Ben-David, Graham, \& Harvey, 2007).

Although most of these studies suggest that inappropriate confidence is related to negative outcomes, there may also be real-world situations in which confidence is beneficial, whether or not it corresponds to actual knowledge or ability.

* Correspondence to: Andrew Parker, RAND Corporation, 4570 Fifth Avenue, Suite 600, Pittsburgh, PA 15213, USA. E-mail: parker@rand.org
For example, even financial advisors who display extreme confidence when making stock market predictions may be preferred by customers over financial advisors who display more appropriate levels of confidence, as compared with their actual performance (Price \& Stone, 2004). Having confidence in one's ability to control business risks that are potentially uncontrollable may also increase managers' willingness to take risks that provide the potential for positive outcomes (March \& Shapira, 1987). This study examines the relationship of confidence, and its correspondence with actual knowledge, with one area of financial decision making-retirement planning.

\section{Evaluating confidence}

The appropriateness of confidence is typically evaluated in comparison with knowledge, and several methodologies have been used to evaluate this correspondence. One common methodology involves asking respondents to answer a set of true/false questions (e.g., "Alcohol causes dehydration"; Bruine de Bruin et al., 2007), expressing their confidence in each answer, item by item, on a half-range scale $(50 \%=$ just guessing, $100 \%=$ absolutely sure) ${ }^{1}$ Alternatively, respondents may be asked to express their overall confidence by providing one single estimate of the percent of items they believe to have answered correctly. In each of these cases, the

\footnotetext{
${ }^{1}$ Other strategies for directly measuring knowledge and confidence include "full-range" assessments, where a single response represents the likelihood of a statement being true or confidence interval assessments, where bounds are selected such that they have a given likelihood of including a focal value.
} 
most common metric is under/overconfidence, which is represented by the difference between overall confidence (assessed either directly or through the mean across items) and actual performance (the percent of correct answers across items). Appropriate confidence, in this sense, is achieved when this difference is zero. That is, if well-calibrated, a person who expresses $70 \%$ confidence in his or her performance, on average, should answer $70 \%$ of the items correctly. Both of these strategies address what Moore and Healy (2008) refer to as "overestimation," reflecting the degree to which individuals' perceptions of their own knowledge (expressed as percent confidence) exceed their actual knowledge (expressed as the percent of correct responses across items).

Other literatures have instead focused on the construct "perceived knowledge," arguably analogous to confidence in knowledge, which is typically assessed via one item asking participants to rate their knowledge on a scale ranging from "very low" to "very high" (e.g., Jaccard et al., 2005; Lusardi \& Mitchell, 2007). Without translating verbal probability expressions into numerical probabilities, such rating scales render it impossible to compute a difference measure of under/overconfidence, which would require that both overall confidence and knowledge are expressed on a $0 \%$ to $100 \%$ scale. An alternative to this difference measure (as well as others that rely on ratio-scaled confidence assessments) is to instead focus on the degree to which confidence varies independently of knowledge (see Jaccard et al., 2005; Parker $\&$ Stone, 2010). Although such a measure of the appropriateness of confidence does not allow for a direct comparison between absolute levels of confidence and knowledge, it is easily computed using regression techniques. Below, we will regress a measure of retirement planning onto measures of both actual financial knowledge and confidence in that knowledge. The marginal coefficient on confidence represents the predictive contribution of unjustified variability in confidence because confidence is varying independently of actual knowledge. This approach also has the advantage of being computable for confidence assessed using ordinal verbal scales, as well as numeric subjective probability scales.

\section{Individual differences in confidence: reliability and validity}

Confidence in knowledge (as well as its appropriateness) has typically been studied as a consequence of experimental manipulations targeting difficulty and procedural variables (see Alba \& Hutchinson, 2000, and Yates, 1990, for many such examples). In contrast to this large experimental literature, relatively few studies have examined individual differences in expressions of confidence. Those studies that have examined individual differences found them to be relatively stable (Blais, Thompson, \& Baranski, 2005; Bornstein \& Zickafoose, 1999; Klayman, Soll, González-Vallejo, \& Barlas, 1999; Stankov \& Crawford, 1996, 1997; West \& Stanovich, 1997; Wolfe \& Grosch, 1990). Overall, studies have suggested that confidence in knowledge is correlated across tasks, even when actual knowledge shows weak correlations across these tasks (e.g., Stankov, 1998; West \& Stanovich, 1997). The appropriateness of confidence also varies reliably with respondent characteristics, with overconfidence being higher among individuals who are older (Crawford \& Stankov, 1996), of lower socioeconomic status (Bruine de Bruin et al., 2007), and have certain psychiatric disorders (Dar, Rish, Hermesh, Taub, \& Fux, 2000; Parker \& Fischhoff, 2005) such as pathological gambling (Goodie, 2005).

The appropriateness of confidence also tends to consistently show modest positive correlations with performance on other decision-making tasks, suggesting a "positive manifold" of decision-making competencies (Bruine de Bruin et al., 2007; Parker \& Fischhoff, 2005; Stanovich \& West, 2000). Individuals with inappropriate levels of confidence, as seen in differences in expressed percent confidence and the percent of accurate responses across knowledge items, are more likely to exhibit framing errors and to violate the rules of probability when judging risks (Bruine de Bruin et al., 2007). Overconfidence has also been related to worse performance in hypothetical economic tasks, such as trading performance (Biais, Hilton, Mazurier, \& Pouget, 2005) and excess market entry (Camerer \& Lovallo, 1999).

Although previous studies have suggested that confidence and its appropriateness are related to real-world outcomes, they have tended to focus on select decisions made in specific convenience samples, and most results are specific to a single method for measuring confidence. Here, we contribute to the existing literature by examining confidence and its appropriateness, along with their relationships with financial decisions related to retirement planning, as faced by a national sample of US adults. Such financial decisions are increasingly complex, presumably requiring financial knowledge and confidence to act on that knowledge.

Participants were recruited through the American Life Panel (ALP), an Internet panel study of US adults aged 18-91 years. The same panel members completed four different surveys designed by different researchers, using different methods to assess knowledge and confidence in knowledge. As such, these data provide a unique opportunity to examine the stability of confidence, its relationship to knowledge, as well as their joint relationships to retirement planning behavior, across time, domain, and method.

\section{METHOD}

Web-based surveys were conducted with RAND's ALP, whose members form a national sample of US adults. They are recruited from among respondents to the University of Michigan's long-standing Survey of Consumer Attitudes, who were originally contacted through random-digit dialing. Michigan respondents willing to participate in Internet surveys and giving consent to have their information shared with RAND were invited to join the ALP. Those without prior Internet access were offered Web TV to provide such access. Panel members receive financial compensation for completing Internet surveys fielded by different researchers, including economists, sociologists, psychologists, survey 
methodologists, and statisticians. Greater detail is available at http://www.rand.org/labor/roybalfd/american_life.html.

\section{Sample}

We analyzed data from four ALP studies, conducted across a 28 -month period. Each study was conducted on overlapping subsamples of the full panel, including 566-1150 participants (Table 1), with 491 respondents completing all four studies. At the time these studies were conducted, a substantial number of panel members were on the rolls but never participated in any survey. After excluding those individuals, each study had a very high response rate $(>90 \%)$. Among the full set of participants who completed at least one the four studies, ages ranged from 18 to 91 years (mean $=53.0$ years), $55.9 \%$ were female, and $49.4 \%$ had a bachelor's degree. As for household family income, $13.7 \%$ had less than $\$ 25000$, $23.9 \%$ had between $\$ 25000$ and $\$ 49999,22.4 \%$ had between $\$ 50000$ and $\$ 74999$, and $40.0 \%$ greater than $\$ 75000$ (Table 1).

\section{Measures}

The four studies were designed by different researchers, using different domains and methodologies, thus allowing us to examine the robustness of results across these approaches (see Table 2). Study 1, designed by Lusardi and Mitchell (2009), included 13 true/false questions of financial knowledge, with overall confidence assessed with a single question assessing perceived knowledge: "how would you assess your understanding of economics" accompanied by a scale ranging from 1 (= very low) to 7 (= very high). Study 2 , designed by Parker and Bruine de Bruin, included a shortened form of the under/ overconfidence instrument designed for the Adult DecisionMaking Competence measure (Bruine de Bruin et al., 2007). It consisted of 14 true/false questions measuring general knowledge (e.g., "alcohol causes dehydration"), with confidence in each answer being assessed on a scale ranging from $50 \%$ (= just guessing) to $100 \%$ (= absolutely sure). Study 3 was designed by Dominitz, Hung, and Yoong (2009) and included a hypothetical fee minimization when investing task that asked respondents to allocate a fixed amount of money among Standard and Poor 500 index funds. These funds are designed to track the market, so none were expected to outperform the others. Hence, performance reflected whether or not respondents' allocations minimized fees, the only distinguishing substantive feature among the funds. The feeminimization-when-investing task provides an indirect assessment of knowledge, because in this task it is trivial to minimize fees once you recognize that is where you should be focusing. Overall confidence was assessed with a single question asking "I am very confident that I made the decisions that would be best for me" followed by a scale ranging from 1 (= disagree strongly) to 5 (=agree strongly). Finally, Study 4 was conducted by Willis and colleagues (Delavande, Rohwedder, \& Willis, 2008; Kimball, 2008; Willis, 2008) and included 70 true/false questions measuring financial sophistication (e.g., "Refinancing your home mortgage

Table 1. Description of subsamples in each study

\begin{tabular}{lllll}
\hline & \multicolumn{1}{c}{ Study 1 } & & \multicolumn{1}{c}{ Study 2 } & Study 3 \\
\hline Sample size & 1150 & 1114 & 1005 & 566 \\
Field dates & May 2006-November 2007 & August 2006-November 2007 & June 2007-September 2008 & July-October 2007 \\
Mean age (range) & $53.6(20-91)$ & $53.4(18-91)$ & $52.8(19-91)$ & $54.6(20-91)$ \\
Female (\%) & 55.4 & 54.9 & 56.1 & 55.6 \\
Bachelor's degree (\%) & 49.8 & 50.1 & 48.3 & 48.4 \\
Household income (\%) & & & & \\
$\quad<25000$ & 13.5 & 13.7 & 14.6 & 13.2 \\
$\$ 25000-\$ 49999$ & 22.6 & 23.1 & 24.5 & 23.5 \\
$\$ 5000-\$ 74999$ & 22.7 & 22.2 & 22.9 & 22.6 \\
$>\$ 75000$ & 41.2 & 41.0 & 38.0 & 40.7 \\
\hline
\end{tabular}

Table 2. Description of measures in each study

\begin{tabular}{|c|c|c|c|c|c|c|}
\hline Study & Domain & $\begin{array}{l}\text { Knowledge } \\
\text { measure }\end{array}$ & $\begin{array}{l}\text { Observed } \\
\text { knowledge }\end{array}$ & $\begin{array}{l}\text { Confidence } \\
\text { measure }\end{array}$ & $\begin{array}{l}\text { Observed } \\
\text { confidence }\end{array}$ & $\begin{array}{c}\text { Confidence-knowledge } \\
\text { correlation }\end{array}$ \\
\hline 1 & $\begin{array}{l}\text { Financial } \\
\text { knowledge }\end{array}$ & $\begin{array}{l}\text { Percent correct across } \\
13 \text { true/false items }\end{array}$ & $\begin{array}{l}\text { Mean }=0.75 \\
(S D=0.21) \\
\alpha=0.77\end{array}$ & $\begin{array}{l}\text { Overall } \\
\text { (1 = very low; } \\
7=\text { very high })\end{array}$ & $\begin{array}{l}\text { Mean }=4.53 \\
(S D=1.26)\end{array}$ & $0.366^{* * *}$ \\
\hline 2 & $\begin{array}{l}\text { General } \\
\text { knowledge }\end{array}$ & $\begin{array}{l}\text { Percent correct across } \\
14 \text { true/false items }\end{array}$ & $\begin{array}{l}\text { Mean }=0.93 \\
(S D=0.10) \\
\alpha=0.66\end{array}$ & $\begin{array}{l}\text { Item by item } \\
(50 \%=\text { just guessing; } \\
100 \%=\text { absolutely sure) }\end{array}$ & $\begin{array}{l}\text { Mean }=0.89 \\
(S D=0.07) \\
\alpha=0.78\end{array}$ & $0.335 * * *$ \\
\hline 3 & $\begin{array}{r}\text { Fee minimization } \\
\text { when investing }\end{array}$ & $\begin{array}{l}\text { Minimizing investment } \\
\text { fees in an experimental } \\
\text { task (yes or no) }\end{array}$ & $\begin{array}{l}32.6 \% \\
\text { minimized } \\
\text { fees }\end{array}$ & $\begin{array}{l}\text { Overall } \\
(1=\text { disagree strongly; } \\
5=\text { agree strongly })\end{array}$ & $\begin{array}{l}\text { Mean }=3.51 \\
(S D=0.89)\end{array}$ & $0.296 * * *$ \\
\hline 4 & $\begin{array}{l}\text { Financial } \\
\text { sophistication }\end{array}$ & $\begin{array}{l}\text { Percent correct across } 70 \\
\text { true/false items }\end{array}$ & $\begin{array}{l}\text { Mean }=0.74 \\
(S D=0.10) \\
\alpha=0.75\end{array}$ & $\begin{array}{l}\text { Item by item } \\
(100 \%=\text { surely true; } \\
100 \%=\text { surely false })\end{array}$ & $\begin{array}{l}\text { Mean }=0.78 \\
(S D=0.11) \\
\alpha=0.97\end{array}$ & $0.534 * * *$ \\
\hline
\end{tabular}

$* * *$ Two-sided $p<0.001$. 
results in added fees and/or points"), with responses given on a 12-point scale. The left side of the scale reflected a belief in the statement being true, ranging from $100 \%$ (= surely true) to $50 \%$ (=guess true). On the right side was the mirror image, ranging from $50 \%$ (=guess false) to $100 \%$ (=surely false). Because the response scale includes true and false versions of $50 \%$, responses can be coded onto the half-range scale used in Study 2 .

At the time of Study 1, respondents also answered three self-reports related to retirement planning: (i) "Have you or your partner ever tried to figure out how your household would need to save for retirement?" $(1=$ yes, $0=$ no); (ii) "Have you consulted a financial planner or advisor or an accountant?" (1=yes, $0=$ no); and (iii) "Have you or your partner developed a plan for retirement saving?" ( $1=$ yes or "more or less," $0=$ no). Questions (ii) and (iii) were only asked if respondents said "yes" to Question (i) and were coded as 0 if Question (i) was "no." Because of the logical dependencies and strong intercorrelations ( $r$ s between 0.59 and 0.90, Cronbach's alpha $=0.88)$, we combined all three responses into a single mean score $(M=0.46, S D=0.44)$, reflecting a retirement planning index. Given that these behaviors probably vary with age, we will control for age in regression analyses below.

\section{Analyses}

For each study, we present descriptive statistics for confidence and knowledge, Cronbach's alpha to reflect the internal consistency for each multiple-item measure of confidence and knowledge, and the Pearson correlation between confidence and knowledge. We computed Pearson correlations across studies (and hence methods) for knowledge and confidence. For each study, we used linear regression to examine how confidence predicted the composite measure of self-reported retirement planning, after controlling for knowledge. We favored this characterization of unjustified confidence (predictive ability of confidence, controlling for knowledge; Parker \& Stone, 2010) over the more common under/ overconfidence score (mean confidence minus percent correct), both because the latter could not be computed for Studies 1 and 3 and because of the potential for both confidence and knowledge to be correlated with the dependent variable in the same direction. Finally, because fee minimization when investing (Study 3) is arguably a behavioral outcome of having more knowledge, it is also an appropriate validation measure. We therefore used logistic regression to examine whether fee minimization when investing was predicted by confidence on the other tasks (controlling for knowledge). To maximize use of the data, parallel crosssectional analyses were run for each study, except where explicit comparisons were made between studies.

\section{RESULTS}

\section{Confidence and knowledge}

Table 2 presents descriptive statistics for the measures of confidence and knowledge, as well as the correlation among the two, within each study. Note that for Studies 2 and 4, confidence and knowledge were assessed on comparable scales, allowing for the computation of under/overconfidence scores, reflecting the difference between confidence and knowledge. In Study 2, respondents were on average $4 \%$ underconfident $(0.89-0.93$; paired $t(1113)=-17.53$, $p<0.001)$, but in Study 4 , they were on average $4 \%$ overconfident $(0.78-0.74$; paired $t(565)=9.81, p<0.001)$, possibly because of differences in task difficulty (see, e.g., Yates, 1990). ${ }^{2}$ Overall, confidence and knowledge were significantly and positively correlated with each other, ranging from 0.30 to 0.53 . Cronbach's (1951) alpha provides an index of the degree to which items in a scale reflect a single underlying dimension (or set of highly correlated dimensions). Five scales in these data include multiple items, with all showing acceptable levels of Cronbach's alpha (0.66-0.97).

Table 3 displays correlations across studies for (i) knowledge and (ii) confidence. Each correlates positively across tasks but most strongly where there were similarities in domain (Studies 1, 3, and 4) or method (Studies 2 and 4).

\section{Relationship between (appropriate) confidence, retirement planning, and fee minimization when investing}

Across all four studies, pairwise correlations between confidence and the retirement planning index were positive ( $r=0.21,0.20,0.19$, and 0.26, respectively; all $p<0.001$ ). As shown in Table 4, confidence predicts retirement planning even after controlling for actual knowledge as well as demographic characteristics. Perhaps surprisingly, retirement planning is more probable with increased confidence, independent of actual knowledge. The demographic characteristics of the participating Internet panel members remain relatively stable across studies and, hence, show the same pattern across studies, with more planning for older, more educated, and wealthier respondents. ${ }^{3}$

Finally, actual fee minimization on the investment task from Study 3 was positively correlated with mean confidence on the three other studies $(r=0.18,0.15,0.26$; $p<0.001$, for Studies 1, 2, and 4, respectively). As shown in Table 5, fee minimization was predicted (via logistic regression) by confidence in Study 4 and was marginally significant in Study 2, after controlling for knowledge in each of those studies, respectively. These are both remarkable because confidence displays a positive correlation with actual behavior, independent of actual knowledge, and because it does so across quite diverse domains (Study 2 used general knowledge, whereas Study 4 focused on economic and financial knowledge).

\footnotetext{
${ }^{2}$ Because the aggregation across items may mask item-level error, we also computed mean Brier scores (Yates, 1990), reflecting the mean squared error between item-level confidence and correctness, which had a mean of $0.07(S D=0.06)$ for Study 2 and a mean of $0.21(S D=0.06)$ for Study 4.
}

${ }^{3}$ Because the retirement planning index was a count with limited number of categories, analyses were repeated using ordinal regression. Results did not differ qualitatively from those with the linear regressions. 
Table 3. Correlations across studies for knowledge and confidence

\begin{tabular}{lccc}
\hline & \multicolumn{3}{c}{ Domain } \\
\cline { 2 - 4 } Domain & $\begin{array}{c}\text { Financial } \\
\text { knowledge }\end{array}$ & $\begin{array}{c}\text { General } \\
\text { knowledge }\end{array}$ & $\begin{array}{c}\text { minimization } \\
\text { when } \\
\text { investing }\end{array}$ \\
\hline
\end{tabular}

\begin{tabular}{llll}
\hline (1) Knowledge & & & \\
Study 1: & & & \\
$\quad$ Financial knowledge & & & \\
Study 2: & $0.29^{* * *}$ & & \\
$\quad$ General knowledge & & & \\
Study 3: & $0.35^{* * *}$ & $0.16^{*}$ & \\
$\quad$ Fee minimization & $0.63^{* * *}$ & $0.33^{* *}$ & $0.38^{* * *}$ \\
Study 4: & & & \\
$\quad$ Financial sophistication & & & \\
$\begin{array}{l}\text { (2) Confidence } \\
\text { Study 1: }\end{array}$ & & & \\
$\quad$ Financial knowledge & & & \\
Study 2: & & & \\
$\quad$ General knowledge & $0.19^{* * *}$ & & \\
Study 3: & $0.31^{* * *}$ & $0.19 *$ & \\
$\quad$ Fee minimization & & & \\
Study 4: Financial & $0.34 * * *$ & $0.42^{* * *}$ & $0.38^{* * * *}$ \\
$\quad$ sophistication & & & \\
\hline
\end{tabular}

$*$ Two-sided $p<0.05$.

$* * p<0.01$.

$* * * p<0.001$.

Table 4. Linear regression of self-reported retirement planning as a function of confidence, knowledge, and demographics

\begin{tabular}{lllll}
\hline & \multicolumn{4}{c}{ Retirement planning } \\
\cline { 2 - 5 } & Study 1 & Study 2 & Study 3 & Study 4 \\
\hline Predictor variables & & & & \\
Confidence & $0.10^{* * *}$ & $0.08^{* *}$ & $0.12^{* * *}$ & $0.10^{*}$ \\
Knowledge & $0.19^{* * *}$ & $0.10^{* * *}$ & 0.02 & $0.07^{+}$ \\
Control variables & & & & \\
Age & $0.12^{* * *}$ & $0.18^{* * *}$ & $0.17^{* * *}$ & $0.13^{* * *}$ \\
Female & $0.08^{* *}$ & 0.01 & 0.02 & 0.00 \\
Bachelor's degree & 0.04 & $0.08^{* *}$ & $0.10^{* *}$ & 0.06 \\
Income: $\$ 25000-\$ 50000$ & $0.07^{*}$ & $0.07^{*}$ & $0.10^{* *}$ & $0.10^{* *}$ \\
Income: $\$ 50000-\$ 75000$ & $0.12^{* * *}$ & $0.13^{* * *}$ & $0.17^{* * *}$ & $0.16^{* * *}$ \\
Income: $>\$ 75000$ & $0.16^{* * *}$ & $0.19^{* * *}$ & $0.21^{* * *}$ & $0.20^{* * *}$ \\
Adjusted $R^{2}$ & 0.18 & 0.14 & 0.14 & 0.15 \\
$F$-statistic & $31.60^{* * *}$ & $23.36^{* * *}$ & $17.04 * * *$ & $13.04 * * *$ \\
\hline
\end{tabular}

Note: Semipartial correlations, corresponding to the marginal regression coefficients, are presented to show effect size.

${ }^{+}$Two-sided $p<0.1$.

$* p<0.05$.

$* * p<0.01$.

$* * * p<0.001$

\section{CONCLUSIONS}

We present parallel analyses within and across four separate studies conducted on overlapping subsamples of the national ALP. The four studies each measured confidence and knowledge but were implemented by four sets of researchers, addressing different research questions at different
Table 5. Logistic regression of fee minimization when investing as a function of confidence, knowledge assessed on other tasks, and demographics

\begin{tabular}{lccc}
\hline & \multicolumn{3}{c}{ Fee minimization when investing } \\
\cline { 2 - 4 } & Study 1 & Study 2 & Study 4 \\
\hline Predictor variables & & & \\
Confidence & 1.05 & $1.02^{+}$ & $1.06^{* * *}$ \\
Knowledge & $1.04^{* * *}$ & $1.03^{* *}$ & $1.08^{* * *}$ \\
Control variables & & & \\
Age & 1.00 & $1.02^{* *}$ & 1.00 \\
Female & 0.82 & $0.60^{* *}$ & 0.88 \\
Bachelor's degree & $1.61^{* *}$ & $1.96^{* * *}$ & 1.25 \\
Income: $\$ 25000-\$ 50000$ & $0.58^{+}$ & 0.76 & 0.56 \\
Income: $\$ 50000-\$ 75000$ & $0.59^{+}$ & 0.82 & $0.49^{+}$ \\
Income: $>\$ 75000$ & 0.75 & 1.29 & 0.72 \\
Nagelkerke & 0.22 & 0.14 & 0.28 \\
$\chi^{2}$ statistic & $133.37^{* * *}$ & $83.85^{* * *}$ & $108.69 * * *$ \\
\hline
\end{tabular}

Note: Odds ratios are presented.

${ }^{+}$Two-sided $p<0.1$.

$* p<0.05$.

$* * p<0.01$.

$* * * p<0.001$

points in time and using different methodologies applied to different domains. As such, the data presented here provide a unique opportunity to examine confidence's relationship with knowledge, its association with retirement planning and the ability to minimize fees when investing (controlling for knowledge), and the robustness of these results across methodologies, domains, and time.

Our main finding is that, contrary to the view of inappropriate confidence as a necessarily negative metacognitive bias, higher confidence (controlling for knowledge) was correlated with more rather than less prudent behavior-both retirement planning and fee minimization when investing. In other words, with the specific behaviors investigated here, it may be more important to be confident than to be appropriately confident (i.e., have confidence that corresponds to actual knowledge). One possibility is that these results are specific to the domain of financial decisions. For example, confidence may be needed to start the possibly overwhelming process of retirement planning or even to make an appointment with a financial planner. Furthermore, when making such plans, individuals with higher levels of confidence may be more likely to carefully read through investment options or make better use of financial planners, thus making it more likely for them to discover that it is possible to minimize fees (see, e.g., Delavande et al., 2008).

However, these results are surprising even within the area of financial decision making, in light of prior results showing a negative association between overconfidence and successful trading behavior (e.g., Barber \& Odean, 2000, 2001; Blais et al., 2005; Moore, Kurtzberg, Fox, \& Bazerman, 1999; Odean, 1999; Statman et al., 2006). Many of those studies, however, infer confidence indirectly through individual characteristics (e.g., Barber \& Odean, 2001) or other behaviors, such as frequency of trading (e.g., Barber \& Odean, 2000; Statman et al., 2006). This raises the possibility 
that they are capturing something other than just confidence or overconfidence (e.g., perhaps, at times, it takes more confidence to hold steady with an investment portfolio rather than to engage in more trades). Here, we assess confidence directly, covarying out directly measured knowledge. ${ }^{4}$

And whereas we are unaware of results showing inappropriate confidence in knowledge being associated with more prudent behavior in other domains, there is reason to believe that it may sometimes be the case. An analogy might be made to self-efficacy and healthy behavior, with selfefficacy possibly representing confidence in the ability to behave in particular ways (e.g., to quit smoking). In theories of health behavior, self-efficacy is generally viewed as a positive set of beliefs, with the general argument that selfefficacy frees up an individual to act (Bandura, 1986, 1997). In this more general sense, confidence may play a role in reducing hesitation and increasing risk taking. Such effects may be adaptive in some environments (as seen here) but may be maladaptive in other environments, such as adolescent sexual or drug-use behaviors (Parker \& Fischhoff, 2005). Furthermore, we are unaware of research on possible downsides to unjustified self-efficacy (or being overself-efficacious), which might be a valuable line of healthbehavior inquiry derived from behavioral decision research. Overall, however, this reinforces the conclusion that confidence may be an important construct in itself, in terms of predicting real-world behavior, even if it is a poor proxy for actual knowledge or ability.

Our study also provides important insights for the measurement of individual differences. Where possible to assess, both confidence and knowledge showed good internal consistency across items, one form of reliability. Confidence and knowledge each correlated positively across the four studies, testifying to the stability of these constructs. Unlike previous studies, which have found stronger correlations among measures of confidence than among measures of knowledge (Crawford \& Stankov, 1996), levels of correlation were similar for the two, and in places stronger for knowledge. Because knowledge on Study 2 is weakly correlated with the rest, this may be due, in part, to the shared economic/financial domain of Studies 1, 3, and 4.

Moreover, across all four studies, confidence correlated positively with knowledge, indicating a degree of metacognitive competence, and one that may be surprising in a domain like finance and savings where feedback is often complex, ambiguous, and voluminous. Nevertheless, the knowledge-confidence correlation was at times only modest, providing a cautionary note for using confidence as a proxy for knowledge (i.e., perceived knowledge), as it has been used in other studies (Park, Mothersbaugh, \& Feick, 1994). A possible conclusion, and one common to behavioral decision research, is that confidence is an imperfect and possibly biased reflection of actual knowledge. An alternate view is that confidence contains at least some predictive

\footnotetext{
${ }^{4}$ Blais et al. (2005) do assess confidence directly but use confidence intervals rather than self-ratings of knowledge. Because this corresponds more closely to "overprecision" (Moore \& Healy, 2008) and our results focus on "overestimation," this distinction may be one source of the differing results.
}

ability untapped by imperfect knowledge tests. That is, knowledge tests may have omitted topics that are relevant to the domain and are included in individuals' perceptions of their knowledge. This explanation applies most clearly in tasks where confidence is assessed holistically (as in Studies 1 and 3), and respondent introspection may extend beyond the specific knowledge items. However, it may even apply to individual items (as in Studies 2 and 4), if beliefs about domain knowledge affect individual-item confidence judgments. Our results do indeed suggest that confidence provides predictive power, above and beyond actual knowledge, as seen in predictions of both self-reported retirement planning and fee minimization on an experimental investment task.

This research has several limitations. First, the analyses are largely cross sectional and correlative in nature, limiting inferences about causality. And whereas it is tempting to conclude that greater confidence results in more prudent investment behavior (whether or not it corresponds to greater knowledge), stronger methods are needed to take these findings beyond correlational evidence. Past work has attempted to manipulate confidence and knowledge (e.g., Sieck \& Arkes, 2005), but such efforts are largely localized and unlikely to have broad effects on long-term planning. Second, our retirement planning dependent variable is based on self-reports, and it is possible that biases in self-reporting are correlated with confidence. However, we obtained similar results with fee minimization when investing, which is not a self-report dependent variable, and the diversity of strategies taken to assess confidence also demonstrates the robustness of the results. Third, only two behavioral measures were used in the current analyses, based on data available in the ALP. In the future, different and stronger measures of good decision making should be sought to extend this line of inquiry.

These results also suggest other fruitful research directions. For example, there is a need to elucidate possible mechanisms by which greater or lesser confidence could influence downstream behavior, such as information search and use, and hesitancy versus willingness to act. Another research question might address interactions between individual differences and task characteristics, recognizing that individuals may react differently to different situations or in different content domains. Finally, there is a need to better understand the situations when greater confidence, controlling for knowledge, corresponds to more adaptive versus maladaptive behavior.

In closing, the results presented here paint a picture of inappropriate confidence in knowledge that is more complex than a simple metacognitive bias. This may be for two reasons. The first lies in the distinction between good decision-making processes and successful decisions (Yates, 1990), such that even if we consider appropriate confidence a better decision process, it may not always systematically lead to better outcomes. The second lies in the presence of multiple, possibly counteracting consequences of confidence, such that negative consequence of this metacognitive bias may be counteracted by other consequences that are positive, at least in this domain. 


\section{ACKNOWLEDGEMENTS}

This paper was sponsored by the RAND Center for Financial and Economic Decision Making and the National Institute on Aging (R01AG20717, P01AG026571). We gratefully acknowledge the insight and support from Arie Kapteyn and Tania Gutsche.

\section{REFERENCES}

Alba, J. W., \& Hutchinson, J. W. (2000). Knowledge calibration: What consumers know and what they think they know. Journal of Consumer Research, 27, 123-156.

Bandura, A. (1986). Social foundations of thought and action: A social cognitive theory. Englewood Cliffs, NJ: Prentice-Hall.

Bandura, A. (1997). Self-efficacy mechanism in human agency. The American Psychologist, 37, 122-147.

Barber, B. M., \& Odean, T. (2000). Trading is hazardous for your wealth: The common stock investment performance of individual investors. The Journal of Finance, 55, 773-806.

Barber, B. M., \& Odean, T. (2001). Boys will be boys: Gender, overconfidence, and common stock investment. Quarterly Journal of Economics, 116, 261-292.

Ben-David, I., Graham, J. R., \& Harvey, C. R. (2007). Managerial overconfidence and corporate policies. National Bureau of Economic Research Working Paper W13711.

Biais, B., Hilton, D., Mazurier, K., \& Pouget, S. (2005). Judgmental overconfidence, self-monitoring, and trading performance in an experimental financial market. The Review of Economic Studies, 72, 287-312.

Blais, A.-R., Thompson, M. M., \& Baranski, J. V. (2005). Individual differences in decision processing and confidence judgments in comparative judgment tasks: The role of cognitive styles. Personality and Individual Differences, 38, 1701-1713.

Bornstein, B. H., \& Zickafoose, D. J. (1999). "I know it I know it, I saw it I saw it": The stability of the confidence-accuracy relationship across domains. Journal of Experimental Psychology: Applied, $5,76-88$

Bruine de Bruin, W., Parker, A. M., \& Fischhoff, B. (2007). Individual differences in adult decision-making competence. Journal of Personality and Social Psychology, 92, 938-956.

Camerer, C., \& Lovallo, D. (1999). Overconfidence and excess entry: An experimental approach. The American Economic Review, $89,306-318$.

Crawford, J. D., \& Stankov, L. (1996). Age differences in the realism of confidence judgments: A calibration study using tests of fluid and crystallized intelligence. Learning and Individual Differences, 8, 83-103.

Cronbach, L. J. (1951). Coefficient alpha and the internal structure of the tests. Psychometrika, 16, 297-334.

Dar, R., Rish, S., Hermesh, H., Taub, M., \& Fux, M. (2000). Realism of confidence in obsessive-compulsive checkers. Journal of Abnormal Psychology, 109(4), 673-678.

Delavande, A., Rohwedder, S., \& Willis, R. (2008, September). Preparation for retirement, financial literacy, and cognitive resources. University of Michigan Retirement Research Center Working Paper 2008-190.

Dominitz, J., Hung, A. A., \& Yoong, J. (2009). How do mutual fund fees affect investor choices? Evidence from survey experiments. RAND Working Paper WR-653.

Goodie, A. (2005). The role of perceived control and overconfidence in pathological gambling. Journal of Gambling Studies, 21(4), 481-502.

Jaccard, J., Dodge, T., \& Guilamo-Ramos, V. (2005). Metacognition, risk behavior, and risk outcomes: The role of perceived intelligence and perceived knowledge. Health Psychology, 24, 161-170.
Kimball, M. (2008, September). Cognition and financial literacy. Willis, R. Presentation at the Conference on Understanding Economic Decision-Making, Jackson Hole, WY.

Klayman, J., Soll, J., González-Vallejo, C., \& Barlas, S. (1999). Overconfidence: It depends on how, what, and whom you ask. Organizational Behavior and Human Decision Processes, 79(3), 216-247.

Lusardi, A., \& Mitchell, O. S. (2007). Financial literacy and retirement planning: New evidence from the RAND American Life Panel. MMRC Working Paper 2007-157.

Lusardi, A., \& Mitchell, O. S. (2009). How ordinary consumers make complex economic decisions: Financial literacy and retirement readiness. National Bureau of Economic Research Working Paper 15350.

March, J. G., \& Shapira, Z. (1987). Managerial perspectives on risk and risk taking. Management Science, 33, 1404-1418.

Moore, D. A., \& Healy, P. J. (2008). The trouble with overconfidence. Psychological Review, 115, 502-517.

Moore, D. A., Kurtzberg, T. R., Fox, C. R., \& Bazerman, M. H. (1999). Positive illusions and forecasting errors in mutual fund investment decisions. Organizational Behavior and Human Decision Processes, 79, 95-114.

Odean, T. (1999). Do investors trade too much? The American Economic Review, 89, 1279-1298.

Park, C. W., Mothersbaugh, D. L., \& Feick, L. (1994). Consumer knowledge assessment. Journal of Consumer Research, 21, 71-82.

Parker, A. M., \& Fischhoff, B. (2005). Decision-making competence: External validation through an individual-differences approach. Journal of Behavioral Decision Making, 18, 1-27.

Parker, A. M., \& Stone, E. R. (2010). Identifying the effects of unjustified confidence versus overconfidence: Lessons learned from two analytic methods. RAND Working Paper (WR-740): http://www.rand.org/pubs/working_papers/WR740.html.

Price, P., \& Stone, E. (2004). Intuitive evaluation of likelihood judgment producers: Evidence for a confidence heuristic. Journal of Behavioral Decision Making, 17(1), 39-57.

Sieck, W. R., \& Arkes, H. R. (2005). The recalcitrance of overconfidence and its contribution to decision aid neglect. Journal of Behavioral Decision Making, 18, 29-53.

Stankov, L. (1998). Calibration curves, scatterplots and the distinction between general knowledge and perceptual tasks. Learning and Individual Differences, 10(1), 29-50.

Stankov, L., \& Crawford, J. (1996). Confidence judgments in studies of individual differences. Personality and Individual Differences, 21(6), 971-986.

Stankov, L., \& Crawford, J. D. (1997). Self-confidence and performance on tests of cognitive abilities. Intelligence, 25, 93-109.

Stanovich, K. E., \& West, R. F. (2000). Individual differences in reasoning: Implications for the rationality debate? The Behavioral and Brain Sciences, 23, 645-726.

Statman, M., Thorley, S., \& Vorkink, R. (2006). Investor overconfidence and trading volume. Review of Financial Studies, 19, 1531-1565.

Stone, E. R., Rittmayer, A., \& Parker, A. M. (2004, November). Exploring the effects of overconfidence in casino blackjack. Poster presented at the Annual Meeting of the Society for Judgment and Decision Making, Minneapolis, MN.

West, R., \& Stanovich, K. (1997). The domain specificity and generality of overconfidence: Individual differences in performance estimation bias. Psychonomic Bulletin \& Review, 4(3), 387-392.

Willis, R. (2008, September). Overview of the cognitive economics survey. Presentation at the Conference on Understanding Economic Decision-Making, Jackson Hole, WY.

Wolfe, R., \& Grosch, J. (1990). Personality correlates of confidence in one's decisions. Journal of Personality, 58(3), 515-534.

Yates, J. F. (1990). Judgment and decision making. Englewood Cliffs, NJ: Prentice Hall. 
Authors' biographies:

Andrew M. Parker is a Social and Behavioral Scientist at the RAND Corporation. His research focuses on individual differences in decision making, risk perception and communication, long-range planning, and crisis decision making.

Wändi Bruine de Bruin is an Assistant Professor at Carnegie Mellon University's Departments of Social and Decision Sciences and of Engineering and Public Policy in Pittsburgh, PA. Her research focuses on judgment and decision making, risk perception and communication, as well as individual differences in decisionmaking competence.

Joanne Yoong is an Economist at RAND, Associate Director of the Center for Financial and Economic Decision Making and a faculty member at the Pardee RAND Graduate School. She received her Ph.D. in economics at Stanford University as an FSI Starr Foundation Fellow, and her AB in economics and applied and computational mathematics from Princeton. Dr. Yoong's work at
RAND is focused on individual decision making with an emphasis on finance, health, and economic development.

Robert Willis is professor in the Department of Economics and research professor in the Survey Research Center and the Population Studies Center of the Institutes for Social Research at the University of Michigan. His current research focuses on the relationship between cognition and individual and household economic decisions and outcomes.

Authors' addresses:

Andrew M. Parker, RAND Corporation, Pittsburgh, PA, USA

Wändi Bruine de Bruin, Department of Social and Decision Sciences, Carnegie Mellon University, Pittsburgh, PA, USA

Joanne Yoong, RAND Corporation, Arlington, VA, USA

Robert Willis, Department of Economics, University of Michigan, Ann Arbor, MI, USA 